\title{
Editorial
}

Wilfried Admiraal*

\section{Special Issue: Stress, Distress and Drop-out Amongst Higher Education Students - How to Deal with Challenges in Higher Education?}

https://doi.org/10.1515/edu-2020-0134

received December 7, 2020; accepted December 7, 2020.

In response to structural economic changes and a move to a global economy in many countries, the imperative is to increase university access in order to develop a highly skilled and technologically capable workforce. While this has resulted in significant improvements in access over the last decade, not all students enter university with the same economic, social and cultural capital. Therefore, access, inclusiveness and well-being for all are key in developments in higher education across the world. Higher Education Institutions (HEIs) are part of the broader social tissue and not just places where students acquire academic skills; they also help students become more resilient in the face of adversity and feel more connected with the people around them. Not least, HEIs are the first place where students experience society in all its facets, and those experiences can have a profound influence on students' attitudes and behavior in life.

Ashighereducation becomesincreasinglycompetitive, students come under more pressure to succeed in their grades, which increases their levels of stress. Research has shown that students in higher education experience a greater degree of stress compared with the general population (Bore et al., 2016). Stress has been linked to mental health problems, which are highly prevalent among the student population and have been shown to impact learning and well-being (Stallman \& King, 2016). A number of factors can affect student retention and wellbeing, including the student's social experience within the higher education environment. Students' sense of belonging to their institutions - personal feelings of connectedness to the institution occurring in academic and social spheres - has come to be recognized as one of the most significant factors in students' success and

*Corresponding author: Wilfried Admiraal, ICLON, Leiden, Netherlands, E-mail: w.f.admiraal@iclon.leidenuniv.nl retention in higher education. There has been substantial research to explore belonging and related concepts such as engagement, integration, student experiences in teaching and learning, satisfaction, and retention. While individual characteristics such as personality and propensity to connect may have some impact, it is also acknowledged that institutional factors play an important role. Elements such as the culture of the university or curriculum design may affect the students' experiences, including their sense of belonging and connection to other students, staff and the institution (Kahu \& Nelson, 2018).

The lockdowns in response to COVID-19 pandemic have interrupted conventional schooling and in many countries online teaching is now a new routine for many students in higher education, but it presents significant challenges. Teachers had to adapt to new pedagogical concepts and modes of delivery of teaching, for which they may not have been trained. Many students experience challenges with respect to keeping a sense of belonging to their peers, staff and institution. Students in the most marginalized groups, who don't have access to digital learning resources or lack the resilience and engagement to learn on their own, are at risk of falling behind. Universities from around the world have been uncertain about how long the COVID-19 crisis will last and how it might affect the mental health of students and faculty.

In sum, students have to cope with many challenges, both inside and outside HEIs, which can have immense consequences varying from poor access, low engagement and feelings of distress to delays and drop-out. Yet these challenges and consequences can be different depending on students' social, cultural, economic and language backgrounds leading to a discrepancy between inclusive access and inclusive outcomes. The papers from this special issue contribute to how higher education can take up this massive challenge of access, inclusiveness and well-being for all.

In the first paper, Edjah and colleagues examine levels of stress amongst students in higher education 
in Ghana. Based on questionnaire data from 500 students, the authors find that a large majority of the students show moderate levels of stress, mostly in the academic domain. High stressors are study pressure, high academic competition and requirements to meet deadlines. Yet the authors conclude that these academic stressors are positively related to students' satisfaction with their academic and social life, and, consequently, enhance students' academic performance. However, institutional stressors, such as overcrowded lecture halls and inadequate learning resources are negatively related to students' satisfaction with academic and social life. The latter findings might lead to an implication that HEIs should further improve their support of students in order to keep them satisfied with what they are doing.

In the study of Behr and colleagues, the authors examine the determinants of student drop-out from higher education in Germany. Based on sophisticated analyses of the German National Educational Panel Study they determine factors related to students' demographic and family background, financial situation, prior education, institutions, and motivation and satisfaction with the study, all potentially influencing student drop-out rates in higher education. A number of factors in all these domains contribute to lower risk of dropping out. Of these, good quality prior education, satisfaction with the study and engagement with the study program have a relatively large and positive impact on reducing risk of dropping out. Although not all determinants can be influenced by HEIs, these findings provide some implications for HEIs they can control.

In the study of Borgonovi and Marconi, OECD data have been re-analyzed on access and inequality in higher education across Europe. The authors base their study on three data sets with information about students' study success, study variables, background variables, such as socio-economic and migrant background, efforts and achievements. Based on these analyses the authors conclude that - over time - inequalities in access to and completion of higher education have decreased, but that inequalities in skill level remain unchanged. The latter means that candidate students have different ambitions and expectations of attending higher education, related to their demographic background. These differences might play a role not only in the decision to access higher education, but also to access different programs within higher education.

Moilanen and colleagues examine day-to-day variability of students' study days in a diary study using mobile devices. Students indicated in their own words what factors they considered had affected their well-being that day. Seven categories of factors have been determined that have either a positive or a negative influence on wellbeing. Of these factors, aspects related to 'Studying' are reported in about $10 \%$ of the cases, having a positive influence (completion of assignments) or negative influence (burden of assignments) on well-being. Four profiles of study days have been determined of which Productive study days and Leisure study days are related to low levels of academic stress, and Intense study days and Inefficient study days are found to be related to high levels of academic stress. Probably the main implication of this study is the awareness of variability in study days, also within one individual student, which could lead to an implication to provide students with more autonomy to do their study in their own pace and sequence.

Ahmed and colleagues focus on the specific target group of international students and examined intercultural conflict as the main factors of students' feelings of stress during their studies. They base their research on interviews with nine international students of Anadolu University in Turkey. The participants reported conflicts because of limited language skills of the locals and their lack of awareness of foreign cultures and values. Yet international students appeared to remain quiet when they faced intercultural conflicts to avoid trouble. This can be understood as a common coping strategy of the international students involved in this study. More positive experiences are reported in interaction with other international students. Implications for the university include the development of intercultural competence in the educational programs of both local and international students.

Finally, Pappa and colleagues take the perspective of consequences of the COVID-19 pandemic for students' well-being in higher education. In this study, 37 students from a Finnish university provided an answer to an open question about the consequences of the COVID19 pandemic on teaching and learning. Two themes are developed to describe students' emotions. First, emotions related to well-being with regard to their friends and family including the need for human interaction and health concerns. The second theme concerns emotions related to students' well-being with regard to their studies, including the importance of social life on campus, decreased motivation and concentration, and degreerelated complications. The main implication might be that university should identify students struggling with social isolation and psychological tensions and support them in social contacts to constructively counter the negative effects of staying at home. 


\section{References}

Bore, M., Pittolo, C., Kirby, D., Dluzewska, T., \& Marlin, S. (2016).

Predictors of psychological distress and well-being in a sample of Australian undergraduate students. Higher Education Research \& Development, 35(5), 869-880.

Kahu, E. R., \& Nelson, K. (2018). Student engagement in the educational interface: Understanding the mechanisms of student success. Higher Education Research \& Development, 37(1), 58-71.

Stallman, H., \& King, S. (2016). The learning thermometer: Closing the loop between teaching, learning, wellbeing and support in universities. Journal of University Teaching and Learning Practice, 13(5), 1-11. 